\title{
MISOPROSTOL FOR INDUCTION OF LABOUR: THE HYDERABAD EXPERIENCE
}

\author{
Amna Memon and Raheel Sikandar
}

\begin{abstract}
OBJECTIVES: To determine the safety and efficacy of Misoprostol for induction of labour in a secondary care set up.

DESIGN: Quasi experimental study.

SETTING: Labour ward at Aga Khan Maternal and Child Care Center, Hyderabad - Sindh, Pakistan from September 2005 to May 2006.

METHODS: Forty women having singleton pregnancy, with indication for induction of labour were enrolled for this study. After a verbal consent, $100 \mathrm{mgm}$ of Misoprostol (1/2 Tablet Cytotec, Searle \& Co. Chicago) was inserted in posterior vaginal fornix and repeated every 6 hourly for a maximum of 3 doses or initiation of active labour. Induction failure, caesarean delivery, uterine hyperstimulation and rupture, and the neonatal outcome were main outcome measures. Data were collected through a pre-designed proforma and analyzed through SPSS software version 10.0.

RESULTS: Labour was successfully completed in 35(87.5\%) women, even when Bishop's score was <4. Induction failure was noted in $\mathbf{2 ( 5 \% )}$ women, however, no case of uterine rupture or severe birth asphyxia was found. Out of these 35 women, 12(31.6\%) delivered within 7-8 hours of initiation of labour. Labour was initiated with 2 doses of $100 \mathrm{mgm}$ Misoprostol in 17(42.5\%) cases.

CONCLUSION: Misoprostol seems to be a safe and effective agent for induction of labour. However, these results should be interpretted with caution because of limited number of women in this series.
\end{abstract}

KEY WORDS: Misoprostol. Induction of labour. Hyperstimulation. Uterine rupture.

\section{INTRODUCTION}

Induction of labour involves the artificial initiation of uterine contractions prior to their spontaneous onset, leading to progressive dilatation and effacement of the cervix and delivery of baby. Women who require labour induction often present with unfavourable cervices which can lead to a prolonged and difficult induction. Pre-induction cervical ripening is often done to increase the likelihood of successful labour induction. Till 41 weeks of gestation, more than $15 \%$ of pregnancies remain undelivered. ${ }^{1-4}$ Induction rates range from $10 \%$ to $25 \%$ in industrialized countries. ${ }^{5}$ Induction of labour can be achieved by a variety of physical and biochemical stimuli designed for the purpose. However, approximately $20 \%$ of women having induction of labor end up with cesarean delivery. ${ }^{6,7}$ Hence, there is a keen interest in developing safer, most cost-effective and more efficient means for induction of labour. In this regard, synthetic prostaglandin has been used for labor induction since very long. Misoprostol, ${ }^{8}$ an $E_{1}$ analogue has also been used extensively because of its low cost, easy availability, easy storage and effectiveness especially in low socioeconomic settings like ours. Though, it has been extensively studied but its usage is not yet licensed because of risk of uterine hyper-stimulation and its consequences. Therefore, we conducted this study to determine the efficacy and safety of Misoprostol for induction of labour in our set up.

\section{SUBJECTS AND METHODS}

This quasi experimental study was conducted at Labour ward of Aga Khan Maternal and Child Care Center (AKMCCC) Hyderabad, Sindh - Pakistan from September 2005 to May 2006. AKMCC is a private sector secondary level hospital with limited research facilities. Study subjects included 40 women with singleton pregnancy for induction of labour. Sampling strategy was non-probability convenient. Inclusion criteria were gestational age >36 weeks, cephalic presentation, patient having reassuring cardiotocograpghy and intact membranes. However, women with previous operative delivery, contraindicated to vaginal delivery and parity of more than 1 were excluded from the study. Multiparous women were excluded from the study because of higher risk of uterine rupture. After an informed consent, women were given $100 \mathrm{mgm}$ of 
Tablet Misoprostol in the posterior vaginal fornix every 6 hours till 3 doses or initiation of active labour. Women were monitored with intermittent cardiotocography. Failure of Bishop's Score to rise by 2 or failure of established labour by 18 hours was taken as failure of induction. More than 4 uterine contractions of 40 seconds in 10 minutes were taken as hyperstimulation. Women with failed induction were offered a choice of being delivered by cesarean section or having another trial of induction following a rest period of 24 hours (provided fetal conditions permit).

\section{RESULTS}

In all, 40 women with different indications for induction of labour were enrolled for this study. Age range of the women was18-35 years (Table I). Twelve women $(31.6 \%)$ delivered within 7-8 hours of initiation of active labour (Table II). Seventeen (42.5\%) women required 2 doses of $100 \mu \mathrm{gg}$ Misoprostol for induction of labour (Table III). Women with Bishop's score 4 or less contributed $62.5 \%(25)$ of sample (Table IV). Induction was failed in only $2(5 \%)$ women. Out of all women, 5 underwent cesarean section. Among these women, 2(5\%) had induction failure, 2 underwent cesarean section due to fetal distress while one because of deep transverse arrest. Other complications were postpartum haemorrhage and hypertonous in $4(10 \%)$ women respectively whereas hypersystole in $2(5 \%)$ women. Neonatal hypoxia was observed in no any case. Labour was successfully completed in 35 $(87.5 \%)$ women even when Bishop's score was less than 4 in $62.5 \%$ of women (Table V).

TABLE I:

AGE DISTRIBUTION OF SUBJECTS $(n=40)$

\begin{tabular}{|c|c|c|}
\hline Age & $\begin{array}{c}\text { Number of } \\
\text { women }\end{array}$ & Percentage \\
\hline$<20$ years & 03 & $3.33 \%$ \\
\hline $20-25$ years & 16 & $43.33 \%$ \\
\hline $26-30$ years & 16 & $43.33 \%$ \\
\hline $31-35$ years & 05 & $10.00 \%$ \\
\hline
\end{tabular}

TABLE II:

DURATION OF LABOUR $(n=38)$

\begin{tabular}{|l|c|c|}
\hline \multicolumn{1}{|c|}{ Duration } & No. of women & Percentage \\
\hline$\leq 6$ hours & 07 & $18.4 \%$ \\
\hline 7-8 hours & 12 & $31.6 \%$ \\
\hline 9-10 hours & 10 & $26.3 \%$ \\
\hline$>10$ hours & 09 & $23.7 \%$ \\
\hline
\end{tabular}

TABLE III:

FREQUENCY OF WOMEN REQUIRING DIFFERENT DOSE REGIMEN $(n=40)$

\begin{tabular}{|l|c|c|}
\hline \multicolumn{1}{|c|}{ Dose } & No. of Women & Percentage \\
\hline Single dose & 13 & $32.5 \%$ \\
\hline 2 doses & 17 & $42.5 \%$ \\
\hline 3 doses & 10 & $25 \%$ \\
\hline
\end{tabular}

TABLE IV:

BISHOP'S SCORE $(n=40)$

\begin{tabular}{|l|c|c|}
\hline Bishop score & No. of women & Percentage \\
\hline$<4$ & 25 & $62.5 \%$ \\
\hline$>4$ & 15 & $37.5 \%$ \\
\hline
\end{tabular}

TABLE V:

COMPLICATIONS $(n=40)$

\begin{tabular}{|l|c|c|}
\hline \multicolumn{1}{|c|}{ Complication } & No. of women & Percentage \\
\hline Failed induction & 02 & $5 \%$ \\
\hline Hyper systole & 02 & $10 \%$ \\
\hline Hypertonous & 04 & $17.5 \%$ \\
\hline $\begin{array}{l}\text { Postpartum } \\
\text { hemorrhage }\end{array}$ & 04 & $10 \%$ \\
\hline $\begin{array}{l}\text { Neonatal } \\
\text { admission }\end{array}$ & 02 & $5 \%$ \\
\hline C-section & 05 & $12.5 \%$ \\
\hline
\end{tabular}

\section{DISCUSSION}

Labour induction is a very important part of obstetric care. Prostaglandin $E_{2}$ has been used effectively since 1968 for this purpose. Cost of prostaglandin $E_{2}$ is quite high compared to Misoprostol $\left(E_{1}\right) \cdot{ }^{9-11}$ Misoprostol has been found safe in induction of labour in resource constrained hospital settings in developing countries like ours, using basic clinical tools for monitoring. ${ }^{12-14}$ Stress of pregnancy and labour increases as women reach near term. Among cases of this study, more consciousness was also noted after 36 weeks of gestation regarding induction of labour on the expected date. The 5-8 hours duration of active labour in this study was quite satisfying and comparable with similar reports from other parts of the country ${ }^{15-18}$ as about $75 \%$ of women delivered with a divided maximum dose of 200 mgms. However, larger doses are reported to be safe for $2^{\text {nd }}$ trimester of pregnancy with good results. ${ }^{19,20}$ Ten women $(25 \%)$ who received higher dose in this study showed hyper- 
tonous in $50 \%$ of cases but this responded well to simple analgesia. Those who did not respond to this higher dose were unable to respond to Dinoprostin as well and had operative delivery. ${ }^{21}$ Misoprostol has proved to be more efficient in stimulating labour compared to Oxytocin and Dinoprostin ${ }^{22}$ but safety still need to be proven. ${ }^{23,24}$ Repeated small doses of 50 microgram every 4 hours has been practiced with good results even in multiparous women ${ }^{25}$ but we were cautious in using even low doses for multiparous women, being in a private hospital. Intracervical Misoprostol 50 microgram has resulted in $90 \%$ success rate in other studies ${ }^{26}$ regardless of Bishop Score and now induction with greater dose is being tried. ${ }^{27}$

In limited resource settings like ours where CTG is the only hi tech-monitoring tool, Misoprostol 100 microgram vaginal insertion resulted in short induction delivery interval and successful induction in majority of cases. Although, hypersystole and hyper tones were commonly observed but without any neonatal compromise. ${ }^{28}$ Four $(10 \%)$ patients had $\mathrm{PPH}$ which is also reported by others ${ }^{29,}$ and need further study.

Poverty and social inequalities among women and children are on increase even in the developed world. Providing a safe and cost effective health care should motivate us to conduct more studies using cost effective and efficient labour inducing agents. This seems near to women's perspective of maternity care. Modern maternity care demand women's participation and such studies no matter how small and lacking advanced statistical testing, can help not only in evidence building but, also in shared decision-making.

We conclude that Misoprostol seems quite safe and effective for induction of labour at least in low parity women and in low socioeconomic settings. With its high success rate, it reduces LSCS rate and neonatal ICU admissions. The success rate no matter very tempting but one should take it with caution. The number of women was small in this study sample. There is tremendous need to carry out large studies to further prove safety and efficacy before its use as regular labour inducing drug.

\section{REFERENCES}

1. Bishop EH. Pelvic scoring for elective induction. Obstet Gynecol. 1964; 24:266-8.

2. Garret WJ. Prognostic signs of surgical induction of labour. Med J Aust. 1960;47:929-31.

3. Brindley BA, Sokol RJ. Induction and augmentation of labour: basis and methods of current practice. Obstet Gynecol Surv. 1988; 43: 730-3.

4. Rogers MS. Induction and augmentation of labor. In: Chamberlain G, Steer P (edi). Turnbull's Obstetrics. Third Edition. Edinburgh: Churchill Livingstone, 2002:Pp. 563-77.
5. Tenore LJ. Methods of cervical ripening. Am J Family Physician. 2003;67: 2123-8.

6. Vahratian A, Zhang J, Troendle JF, Sciscione AC, Hoffman MK. Labor progression and risk of cesarean delivery in electively induced nulliparas. Obstet Gynecol. 2005;105(4):698-704.

7. Hoffman MK, Vahratian A, Sciscione AC, Troendle JF, Zhang J. Comparison of labor progression between induced and non-induced multiparous women. Obstet Gynecol. 2006; 107(5): 1029-34.

8. Wing DA. Labour induction with misoprostol. Am J Obstet Gynecol. 1999;181:339-45.

9. Keirse MJNC. Prostaglandins cervical ripening: Meta analysis of world wide clinical experiences. J Reprod Med.1993;38:89-100.

10. Harms K, Nguyen C, Toy EC, Baker B. Intravaginal misoprostol versus cervidil for cervical ripening in term pregnancies. Obstet Gynecol. 2001; $97(4$ suppl):36.

11. Jawaid SA. Proceedings of an advanced course in gynecology. Pak J Med Sci. 2001; 17:177-188.

12. Loto OM, A. Fadahunsi A, Kolade CO. Safety and efficacy of misoprostol for induction of labour in a semi-urban hospital setting. J Obstet Gynaecol 2004; 24(6): 638-40.

13. Ezechi OC, Kaly BK, NjoKanuma FO, Nowokoro CA, Okeke GC. Vaginal misoprostol induction of labour; a Nigerian hospital experience. J Obstet Gynecol. 2004; 24(3): 239-42.

14. Yolande $H$, Namory $K$, Delphine F, Mamadou Hady D, Mamadou Dioulde B, Daneil T, et al. Misoprostol use for labour induction in developing countries: a prospective study in Guinea. Eur J Obstet Gynaecol. 2005;122(1):40-4.

15. Kallue UR. Sultana N. Vaginal Misoprostol-the revolutionary starter switch in induction of labour. Pak Armed Forces Med J. 2004; 54(2):202-4.

16. Hassan AA. A comparison of oral misoprostol tablets and vaginal prostaglandins E2 pessary in induction of labour at term. J Coll Physicians Surg Pak. 2005;15(5):284-7.

17. Jehan A, Noorani M. Induction of labour with oral misoprostol for prelabour rupture of membrane at term. J Pak Med Assoc. 2005; 55(5):180-3.

18. Mazhar SB, Sarwar S, Mehmood G. Induction of labour, a randomized trial comparing PGE pessary, intracervical Foleys catheter and extra amniotic saline infusion. J Surg (Pims). 2000; 19 \& 20:12-8.

19. Kamal R, Parveen F, Syeda BM. Role of vaginal misoprostol in vaginal versus double oro-vaginal route for termination of pregnancy in mid trimester pregnancy. Ann Pak Inst Med Sci. 2005;1(4):196200. 
20. Javed L, Malik M, Jamal N, Shaikh S, Farzana F. Mid trimester termination of pregnancy - Comparision of sublingual with vaginal misoprostol. Biomedica. 2004; 20(1):56-9.

21. Saleem S. Efficacy of Dinoprostone, intracervical foleys and misoprostol in labor induction. J Coll Physicians Surg Pak. 2006; 16 (4): 276-279.

22. Mozurkewich E, Horrocks J, Daley S, Von Oeven $P$, Halvorson M, Johnson M, Zaretsky M, Tehranifar M, Bayer-Zwirello L, Robichaux A MisoPROM study: a multicenter randomized comparison of oral misoprostol and oxytocin for premature rupture of membranes at term. Am J Obstet Gynecol. 2003;189(4):1026-30.

23. Alfirec Z. Oral misoprostol for induction of labour; Cochrane Database Systemic Review. 2001; (2):CD1338.

24. Prozhanova V, Sampat D, Porozhanova K. Misoprostol and induction of labour. Akush Ginekol (sofiia) 2005;44(5):27-30. (Article in Bulgarian)

25. Zeteroglu S, Sahin HG, Sahin HA. Induction of labour in great grand multipara with misoprostol.
Eur J Obstet Gynecol Reprod Biol. 2006;126 (1):27-32.

26. Liu HS, ChuTY, Chang YK, Yu MH, Chen WH. Intracervical misoprostol, an efficient method of labour induction at term. Int J Gynecol Obstet. 1999; 64:49-53.

27. Castaneda CS, Izquierdo Puente JC, Leon Ochoa RA., Plasse TF, Power BL, Rayburn WF. Misoprostol dose selection in a controlled release vaginal insert for induction of Labour in nulliparous women. Am J Obstet Gynecol. 2005;193:1071-5.

28. Ozden S, Delikara MN, Avci A, Ficicioglu C. Intravaginal misoprostol versus expectant management in premature rupture of membrane with low Bishop score. Int J Gynecol Obstet. 2002; 77:10915.

29. Hofmeyr GJ. Induction of labour with misoprostol. Current Opinion in Obstet \& Gynecol. 2001; 13:577-581.

30. Nahar S, Begum S, Yasnur S and Rasul CH. Use of Misoprostol for induction of labour in unfavourable cervix in eclampsia. Pak J Med Sci.2004; 20 (3):181-85.

AUTHOR AFFILIATION:
Prof. Amna Memon
Department of Gynaecology and Obstetrics
Liaquat University of Medical and Health Sciences
(LUMHS) Jamshoro, Sindh-Pakistan.
Dr. Raheel Sikandar (Corresponding Author)
Assistant Professor
Department of Gynaecology and Obstetrics
LUMHS Jamshoro, Sindh-Pakistan.
Email: pirehsk@yahoo.com

